DOI

\title{
ОСОБЕННОСТИ ПРОИЗВОДСТВА И ПРИМЕНЕНИЯ НОРИЛЬСКИХ ОКСИЛИКВИТОВ В ГОДЫ ВЕЛИКОЙ ОТЕЧЕСТВЕННОЙ ВОЙНЫ
}

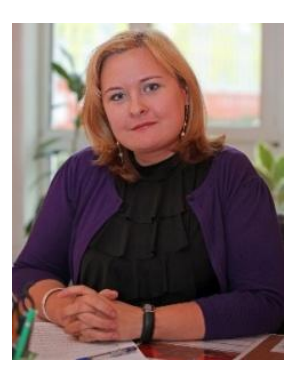

\author{
Н.С. Бояркина, \\ заместитель директора \\ Музейно-выставочного комплекса \\ «Музей Норильска», Норильск \\ zam_nauka@norilskmuseum.ru
}

Аннотация. Оксиликвиты - одна из ярких и трагических страниц в истории Норильского промышленного района. Для его изучения в 1942 г. была открыта лаборатория, а затем построен оксиликвитный завод, где с июня 1943 г. началось промышленное применение оксиликвита. С его помощью за первые три года применения в карьере рудника открытых работ «Угольный ручей» раздробили свыше миллиона тонн горной массы. Каждые 700 граммов оксипатронов заменяли килограмм аммонита. Впоследствии новую взрывчатку стали использовать и на других открытых рудниках Норильского комбината. Пока не отказались от нее в 1957 г.

Ключевые слова: оксиликвит, оксипатрон, взрывчатка, Норильск, история Норильска, норильский комбинат, оксиликвитный завод.

\section{FEATURES OF PRODUCTION AND USE OF NORILSK OXYLIQUIT DURING THE GREAT PATRIOTIC WAR}

\author{
Natalia Boyarkina, \\ Deputy Director of the Municipal Budgetary Institution \\ Museum Exhibition Complex "Norilsk Museum", Norilsk \\ zam_nauka@norilskmuseum.ru
}

\begin{abstract}
Oxygen explosives or oxyliquits represent bright and tragic pages in the history of the Norilsk industrial region. In 1942 a laboratory had been established to study the matter, and then an oxyliquit plant was built
\end{abstract}


where the industrial use of oxyliquit began in June 1943. With its help, in the first three years of use in the quarry of Coal Stream open - pit mine, over a million tons of rock mass were crushed. Every 700 grams of oxygen cartridge replaced a kilogram of ammonite. Subsequently, new explosives began to be used at other open - pit mines of the Norilsk Combine until it was abandoned in 1957.

Keywords: oxygen explosive, oxyliquit, oxygen cartridge, explosive, Norilsk, Norilsk history, Norilsk Combine, oxyliquit plant.

Впервые оксиликвиты (от латинского oxygenium - кислород и liquidus - жидкий) применили в Италии в 1899 г. во время строительства Симплонского тоннеля в Альпах. Затем взрывчатку на жидком кислороде использовали Франции в 1914-1918 гг. [1, с. 2], в Китае, Корее, в Чили и в США [2, с. 2]. В 1927-1933 гг. их начали применять в СССР - на строительстве ДнепроГЭСа, а во второй половине тридцатых - при добыче медной руды в Коунраде [3, с. 3]. Однако несколько неожиданных взрывов, унесших человеческие жизни, остановили применение оксиликвитов в СССР.

Решено было вернуться к ним в 1938 г. в Норильске, когда по настоянию Авраамия Павловича Завенягина был взят курс на разработку месторождений методом открытой горной добычи.

Авраамий Павлович приехал в строящийся поселок Норильск в апреле 1938 г. для вступления в должность начальника Норильскстроя и ИТЛ НКВД СССР [4, с. 800]. Он понимал важность создания хорошей рудной базы для будущего металлургического производства, значение четкой организации и механизации работ и он считал ошибочным первоначальное решение о строительстве в Норильске поселка на две тысячи жителей исключительно для мужчин, со сменой людей через три года. Поэтому Авраамий Павлович внес проектировщикам ряд предложений, одно из которых касалось организации вместе с подземной открытой добычи угля и руды [5, с. 164].

Огромный масштаб открытых горных работ в суровых условиях Заполярья, оторванность Норильского комбината от транспортных магистралей потребовали принятия принципиально новых решений при выборе взрывчатого вещества. Необходима была разработка и освоение нового местного мощного и экономичного взрывчатого вещества, поэтому горняки пришли к выводу о необходимости применения оксиликвитов. Однако ни в советской, ни в 
зарубежной практике взрывных работ не было до сих пор безопасных и простых в обращении оксиликвитов, что вынудило создавать новый оксиликвит собственными силами [1, с. 3].

С этого времени начинается работа над техническим проектом комбината по изготовлению в Норильске оксиликвитов для открытых горных разработок (рис. 1).

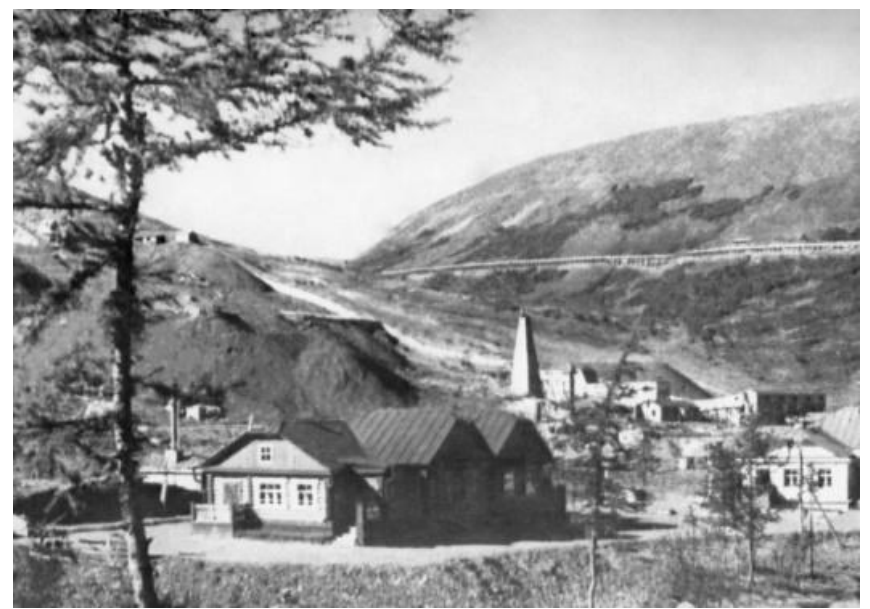

Рис. 1. Панорама Норильска. 1938 г.

Проект предусматривал применение сложного поглотителя из смеси $60 \%$ активированного угля, $30 \%$ торфа и $10 \%$ металлического порошка (чугунных опилок), помещенного в специальную оболочку из мешковины. Экспертиза с участием известный ученого, академика А.А. Скочинского одобрила проект, указав на необходимость предварительного проведения ряда научно-исследовательских работ с оксиликвитами в Норильске.

В марте 1942 г. была организована исследовательская группа и создана Норильская оксиликвитная лаборатория [1, с. 10]. Её открыли в здании, построенном на одном из склонов горы Рудной.

С этой лаборатории, организаторами которой были инженеры Алексей Дмитриевич Яхонтов и Юрий Натанович Зинюк, и началось многолетние исследования и самое широкое промышленное применение оксиликвитов. 
Горный инженер Яхонтов - молодой инженер и доцент Московского горного института, был направлен в Норильск в конце 1941 г. и назначен начальником оксиликвитного завода, только еще рождавшегося в чертежах проектной конторы комбината. Начал он с подбора кадров. Естественно, что специалистов столь редкой области в Норильске не было. Но нашлись люди, знакомые с взрывчаткой [16, с. 17].

С первых дней существования оксиликвитной лаборатории её начальником стал Юрий Натанович Зинюк, активно возглавив все исследования. Заключенный Норильлага Зинюк - в прошлом артиллерийский инженер-химик, ленинградец, участник Гражданской войны. В 1932 г. окончил Военно-техническую академию им. Дзержинского. До ареста в 1937-м - крупный инженер, прирожденный исследователь, один из авторов проекта и ведущих инженеровхимиков Кемеровского комбината - первенца химической промышленности СССР. С июня 1939 г. Ю.Н. Зинюк отбывал в Норильске десятилетний срок по целому «букету» пунктов 58-й статьи [7, с. 2].

Оксиликвитная лаборатория начала свою работу с детального изучения намеченных составных частей поглотителя: активированного угля и торфа - сфагнума.

В ходе исследовательских работ, в которых приняли активное участие заключенные Норильлага, было установлено, что запроектированный состав основы оксиликвита - поглотитель жидкого кислорода - можно заменить лучшим, более дешёвым и целиком местным - одним мхом-сфагнумом, которого в норильской тундре неисчислимое множество $[8$, c. 1]. Это избавляло комбинат от необходимости завоза большого количества дерева крепких пород и строительства установки для получения активированного угля [1, с. 11].

Летом 1942 г. на горе Рудной, неподалёку от лаборатории, начали строить оксиликвитный завод. К осени строительство развернулось полностью.

Одновременно продолжались исследовательские работы, которые показали, что мох-сфагнум не нуждается в измельчении, как планировалось первоначально, гораздо лучше использовать его в естественном волокнистом состоянии, спрессовав в патроны (рис. 2). 
Технология производства поглотителя от этого значительно упростилась [9, с. 14].

Выяснилось, что оксиликвит на мхе сфагнуме обладал хорошими взрывчатыми свойствами, был более мощным, безопасным, менее чувствительным к случайному удару и другим воздействиям, вызывавшим неожиданные взрывы, и оксипатрон не требовал оболочки [10, с. 23].

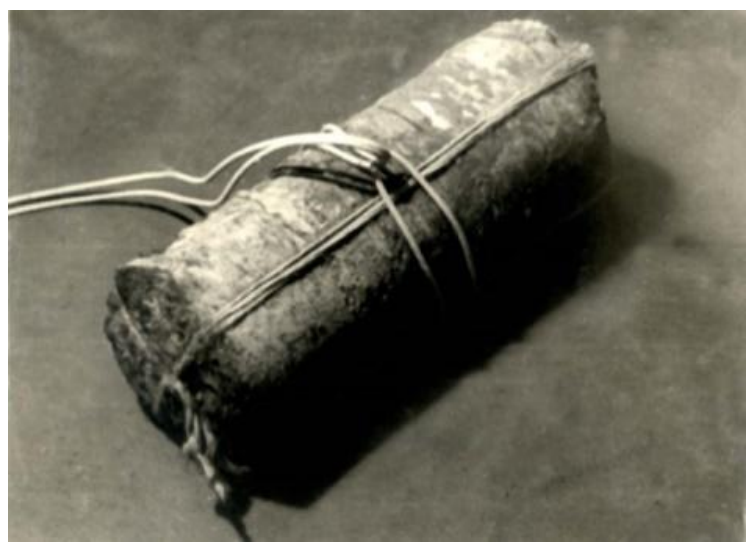

Рис. 2. Оксипатрон

К весне 1943 г., когда в обоих цехах оксиликвитного завода начали монтировать оборудование, заключенные Норильлага Антон Сильверстович Вейшнер, Марк Шевельевич Кантор, бывший студент-механик, и Анатолий Иванович Муратов, прибывший с Соловков слесарь-инструментальщик, получивший десять лет по 58-й статье, с помощью техника-электрика Николая Евгеньевича Демина, который первую часть срока отбывал на строительстве Комсомольска-на-Амуре, сконструировали и изготовили прессы для промышленного производства патронов мха-сфагнума. Размеры, плотность и другие параметры патронов были рассчитаны в лаборатории. Прессы смонтировали в цехе поглотителей, проект которого был создан заново, и начали штамповать торфяные цилиндры. Началось промышленное изготовление прессованных оксипатронов. 


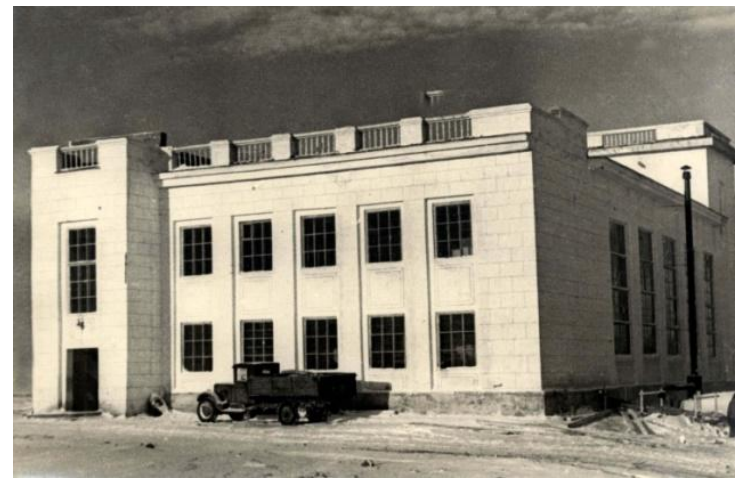

Рис. 3. Оксиликвитный завод в Норильске. 1942 г.

В самом начале лета пустили кислородную установку ВАТ (Всесоюзного автогенного треста), эвакуированную в Норильск из Днепропетровска, - аппарат мощностью 130 кубометров газа в час - и начали выработку жидкого кислорода (рис. 3,4$)$.

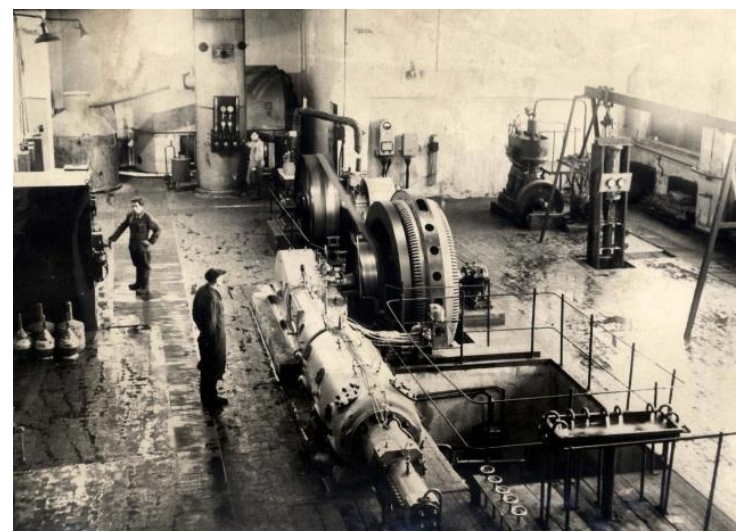

Рис. 4. Внутренний вид цеха жидкого кислорода Оксиликвитного завода. 1940-е гг.

В середине 1943 г. было проведено несколько опытных взрывов скважин на полигоне, и 23 июня 1943 г. был осуществлен первый опытно-промышленным взрыв скважин на руднике «Угольный ручей». Первоначально, как и было предусмотрено проектом, сухие патроны поглотителя опускали в скважины, про- 
буренные на уступах рудника. Над каждой скважиной устанавливали бак с жидким кислородом и выливали его внутрь скалы на патроны [11, с. 16]. Это была сравнительно безопасная система зарядки. Не надо было манипулировать с патронами оксиликвита он образовывался внутри скважины. Но большая часть кислорода уходила на охлаждение скважин, качество полученного оксиликвита не поддавалось контролю, взрывали его вслепую, то пересыщенным, то недонасыщенным. В результате горная масса рыхлилась неравномерно [12, с. 28].

Тем же летом, после нескольких взрывов А.Д. Яхонтов и Ю.Н. Зинюк от этой технологии отказались. В лаборатории срочно изучили и опробовали более совершенный способ, которым и пользовались затем несколько лет.

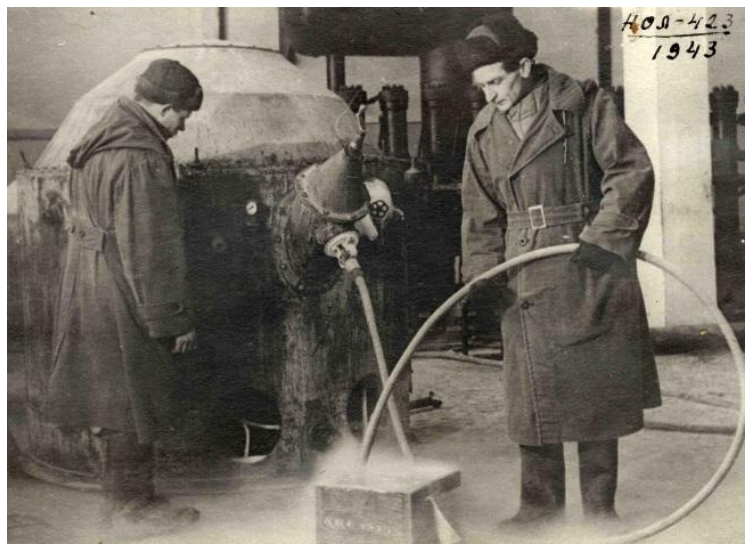

Рис. 5. Насыщение кислородом оксипатронов (справа Ю.Н. Зинюк). 1943 г.

Патроны поглотителя заливали кислородом в специальных ящиках - термосах, которые по чертежам М.Ш. Кантора изготовляли в механической мастерской завода (рис. 5). Везли заполненные ящики в карьер, там извлекали патроны крючками, осторожно переносили к скважинам и опускали в них на других крючках. Несколько патронов в каждой скважине обматывали детонирующим шнуром, его концы соединяли в общую сеть с капсюлями-детонаторами [13, с. 37]. Когда все скважины были заполнены и сеть смонтирована, поджигали бикфордов шнур или включали взрывную электрическую машинку, подсоединенную к тонким прово- 
дам электрокапсюлей, и производили взрыв. Всё, за исключением капсюлей, детонирующего шнура, проводов и машинок, изготавливали на оксиликвитном заводе [6, с. 206].

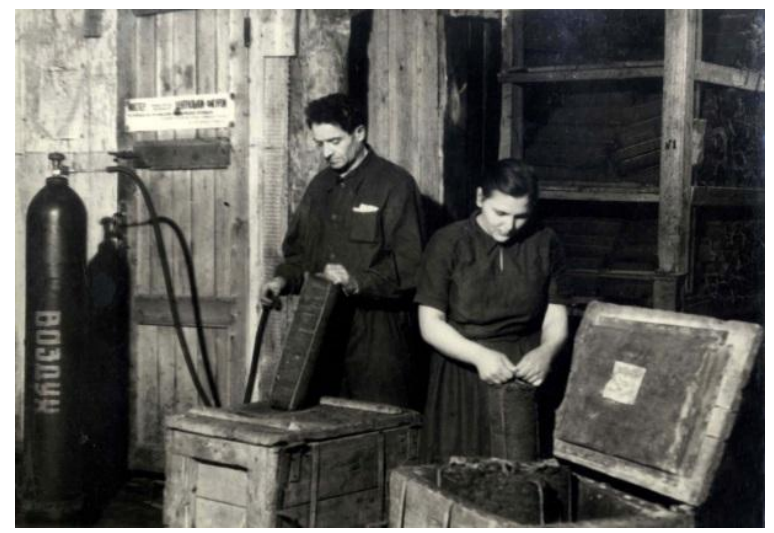

Рис. 6. Закладка патронов из торфа-сфагнума в термосы для перевозки к месту взрыва. 1944 г.

С этого времени началось промышленное применение оксиликвита на открытых горных работах в Норильске. Оксиликвит применялся на самых разнообразных видах взрывных работ: массовое взрывание скважин канатно-ударного бурения, взрывание колодцев, шпуров при проходке минных штолен при прострелке скважин и дроблений негабаритов после массовых взрывов твердой взрывчаткой [14, с. 24].

Месяц от месяца применение оксиликвита расширялось. Стало возможным отказаться от привоза в Норильск многих сотен тысяч тонн так называемой твердой взрывчатки - аммонитов, тротила и т.д., которые нужны были фронту (рис. 6-8).

За первые три года применения на руднике «Угольный ручей» взорвали более четырехсот тонн оксиликвита, вскрыв свыше миллиона тонн горной массы самых крепких пород [15, с. 106].

Строительство в Норильске завода для оксиликвитов, изобретение нового, более эффективного их сорта, разработка технологии его заводского изготовления, проведение без помощи учёных центра сложнейших и опаснейших опытов по изучению всех свойств нового оксиликвита, проектирование, испытание и вне- 
дрение в горные работы технологии его применения - имело огромную государственную значимость (рис. 9).

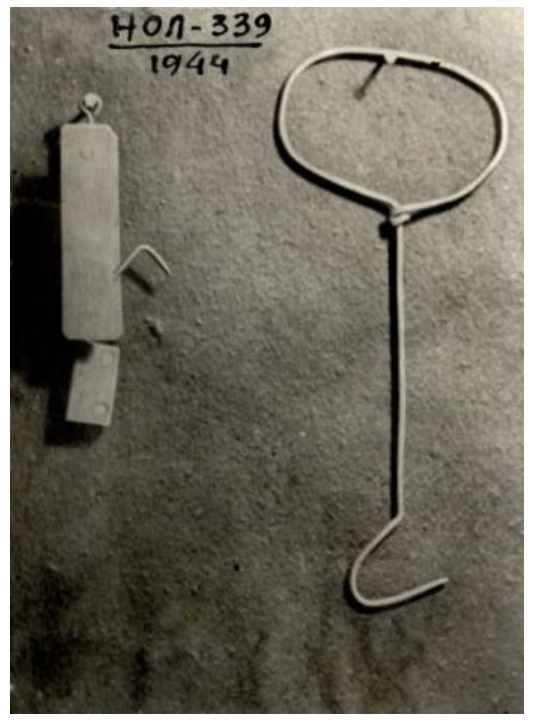

Рис. 7. Крючок для выемки оксипатронов из термосов. 1944 г.

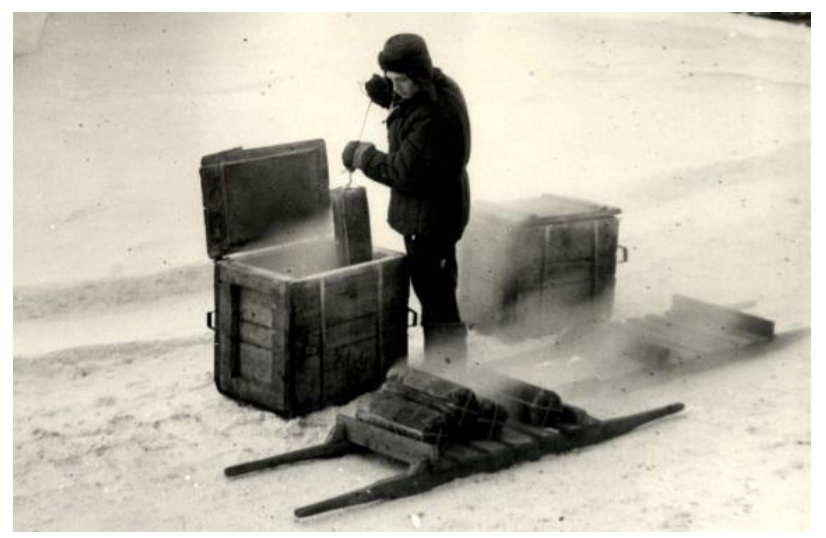

Рис. 8. Выемка насыщенных кислородом оксипатронов. 1944 г. 
Летом 1944 г. оксиликвитный завод посетил А.П. Завенягин, уже в должности заместителя Народного комиссара внутренних дел СССР, и остался доволен проведенной работой, высоко оценив деятельность А.Д. Яхонтова, Ю.Н. Зинюка и руководимых ими коллективов. А позже в этом же году Главным управлением горнометаллургической промышленности НКВД СССР были рассмотрены и утверждены НКВД СССР «Временные правила производства и применения оксиликвитов на открытых горных работах», разработанные Норильским комбинатом [16, с. 1].

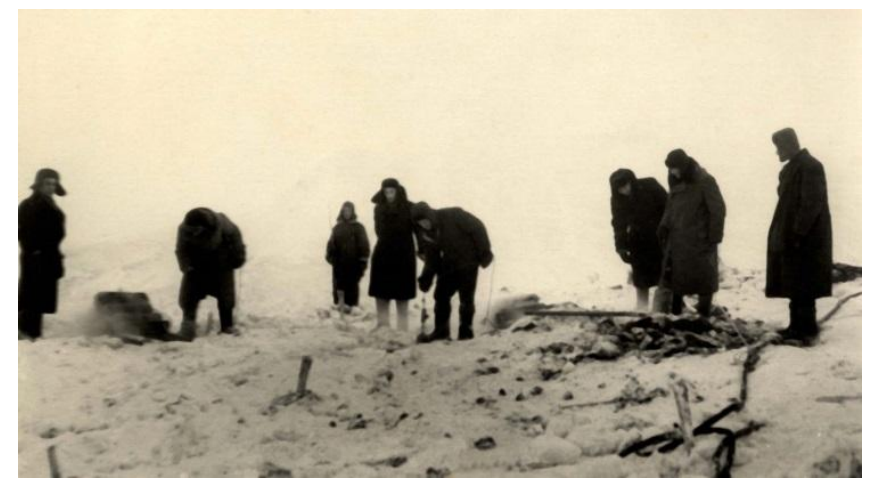

Рис. 9. Заряжение скважин оксиликвитом на руднике «Гора Рудная». 1944 г.

В 1945 г. А.Д. Яхонтов участвовал с докладом на заседании технического совета Главкислорода при Совнаркоме СССР. Московское научное сообщество высоко оценило работу норильчан, отразив свое мнение в протоколе заседания за подписью председателя технического совета академика П.Л. Капицы:

«СЛУШАЛИ: Промышленное применение оксиликвитов на Норильском никелевом комбинате - доклад начальника оксиликвитного завода Норильского комбината А.Д. Яхонтова.

РЕШИЛИ: Доклад инж. А.Д. Яхонтова о промышленном применении оксиликвитов на Норильском никелевом комбинате принять к сведению.

Отметить инициативу работников Норильского никелевого комбината НКВД, успешно осуществивших в промышленном 
масштабе использование жидкого кислорода для производства горно-взрывных работ.

Считать желательным организацию экспериментального производства и применения оксиликвитов еще на одном руднике (помимо Норильского комбината и Коунрадского рудника) для проверки спорных моментов, возникших в результате опытов, проводимых в различных почвенно-климатических условиях.

Просить Горный институт Академии наук СССР (академика Скочинского) детально обсудить в среде специалистов опыт промышленного применения оксиликвитов на Норильском никелевом комбинате, выявить неясные вопросы и наметить необходимые мероприятия по разрешению этой важной народнохозяйственной проблемы» [17, с. 1].

Тем временем оксиликвит в Норильске применялся уже не только на горных работах, но и в строительстве. Когда начинали возводить одно из крупнейших сооружений Норильска - Большую обогатительную фабрику - им пользовались для изготовления огромных котлованов под фундаменты.

Работа по его изучению и применению в Норильске была удостоена в 1950 г. высокой государственной награды. В центральных газетах было опубликовано постановление Совета Министров СССР о присуждении Сталинских премий видным деятелям науки и техники, литературы и искусства. Список лауреатов вошли известные в Норильске начальники. Им присудили премию третьей степени с формулировкой «за коренные усовершенствования методов производства открытых горных работ», слов «норильский оксиликвит» в постановлении Совмина не было.

Алексея Дмитриевича Яхонтова по формальным причинам не включили даже в предварительные списки кандидатов на Сталинскую премию. Фамилии Ю.Н. Зинюка и других заключенных Норильлага, представленных на награждение и указанные в документах, бесследно исчезли, а позже приказом начальника комбината и ИТЛ НКВД СССР им были оформлены денежные премии «за участие в разработке и применении оксиликвита» ... [16, с. 251]

За время применения оксиликвитов на предприятиях Норильского комбината при его помощи было взорвано более 8 млн тонн горной массы и было изготовлено 688 тонн оксиликвитов $[18$, c. 30$]$. Его выпуск прекратили и перешли на производство ки- 
слорода только в 1957 г. [19, с. 2; 20], но за эти годы оксиликвит с честью выполнил свою историческую для комбината миссию (рис. $10)$.

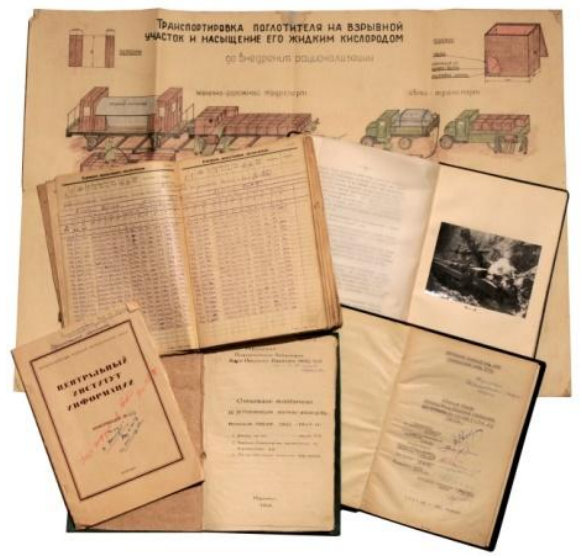

Рис. 10. Материалы оксиликвитного завода из фондов Музея Норильска

\section{Список литературы и источников}

1. Итоги научно-исследовательской работы оксиликвитного завода «Оксиликвиты на открытых горных разработках» за подписями В.С. Зверева, И.В. Усевича, Ю.Н. Зинюка. - Норильск, 1948. 214 с. // ПИ МН. ОФ 6309.

2. Норильский С.Л. Замечания по работе Ассонова и Марченко «Обобщение отечественного и иностранного опыта применения оксиликвитов в горной и строительной промышленности». Норильск, 1949. - 18 с. // ПИ МН. ОФ 3463.

3. Технический отчет № 173 по теме «Разработка методов применения оксиликвитов в условиях открытых горных работ Коунрадского рудника». - М., 1943. - 50 с. // ПИ МН. ОФ 6314.

4. Завенягина Е.А., Львов А.Л. Завенягин. Личность и время. - М.: МИСИС, 2006. -872 с.

5. Алкацев Д.К., Трошев Ж.П. Авраамий Завенягин. - Красноярск: Красноярское книжное издательство, 1975. - 327 с.

6. Норильский С.Л. Сталинская премия. - Тула: Филиппок, 1998. 254 с. // Фонд редкой книги Музея Норильска. ОФ 12720/88. 
7. Автобиография Зинюка Юрия Натановича. - Л., 1987. 7 c. // Письменные источники Музея Норильска (ПИ МН). ОФ 6332.

8. Норильский С.Л. Черновик статьи «Норильский оксиликвит». - Тула, 1969. - 2 с. // ПИ МН. ОФ 13210/15.

9. Новая схема изготовления и применения непатронированных оксиликвитов на открытых горных и строительных работах. Норильск, 1942. - 53 с. // ПИ МН. ОФ 8183.

10. Дневник опытных работ по взрыванию оксиликвитами. Норильск, 1942. - 47 с. // ПИ МН. ОФ 3464.

11. Графические и чертежные материалы по изготовлению и применению оксиликвита. Материалы Норильской оксиликвитной лаборатории 1947-1950 годов. - Норильск, 1951. - 49 с. // ПИ МН. ОФ 8159.

12. Докладная записка о внедрении оксиликвитных взрывчатых веществ. - Норильск, 1943. - 40 с. // ПИ МН. ОФ 3468.

13. Отчетные материалы по результатам научно - исследовательских работах в 1942-1943 годах. - Норильск, 1948. - 70 с. // ПИ МН. ОФ 3474.

14. Материалы по производству и применению оксиликвита для взрывания на открытых горных работах Норильского комбината. - Норильск, 1948. - 83 с. // ПИ МН. ОФ 8158.

15. Оксиликвит на открытых горных разработках. Таблица опытов Норильской оксиликвитной лаборатории в 1942-1948 годах. - Норильск, 1948. - 147 с. // ПИ МН. ОФ 6316.

16. Временные правила производства и применения оксиликвитов для взрывания на открытых горных работах. - Норильск, 1944. - 29 с. // ПИ МН. ОФ 6321.

17. Протокол совещания при начальнике производственнотехнического отдела Главного управления горно-металлургических предприятий НКВД СССР. - М., 29.06.1945. - С. 2. // ОФ $8180-5378$.

18. Важнов М.Я. Норильский промышленный комплекс: этапы и перспективы развития. - Норильск, 1987. - Ч. 1. - 48 с.

19. Обращение коллектива рабочих и инженернотехнических работников Оксиликвитного завода к общественным организациям и администрации рудника «Медвежий ручей». - Норильск, 09.01.1956. - 2 с. // ПИ МН. ОФ 13060/5.

20. Информация № 471 «Применение оксиликвитов на железных рудниках Лотарингии». - М, 1957. - 31 с. // ПИ МН. ОФ 6323. 